\title{
SPATIAL DECAY AND BLOW-UP FOR SOLUTIONS TO SOME PARABOLIC EQUATIONS IN THE HALF CYLINDER
}

\author{
YAN LIU AND CHANGHAO LIN
}

Abstract. In this paper,the spatial behaviors of a nonlinear and a quasi-linear parabolic equations with nonlinear boundary conditions are studied on a half cylinder.Under suitable conditions, we get a various, but closely related forms of Phragmén-Lindelöf principle, and we have proved the smooth solution either fails to exist globally, or when it does exist globally,it must tend asymptotically to zero with increasing long distance along the cylinder from the base.

Mathematics subject classification (2010): 35B50, 35K55, 35K60.

Keywords and phrases: Spatial blow-up, Decay estimates, Nonlinear parabolic equation, Quasi-linear parabolic equation, Initial-boundary conditions.

\section{REFERENCES}

[1] K. A. AMES, Continuous dependence on modelling and non-existence results for a Ginzburg-Landau Equation, Math. Mech. Appl. (2000), Sci 23, 1537-1550.

[2] K. A. Ames And B. Straughan, Non-standard and Improperly Posed Problems, Academic Press, San Diego, 1997.

[3] B. A. Boley, Some observations on Saint-Venant's principle, Proc. 3rd U. S. Nat. Cong. Appl. Mech. ASME, New York (1958), 259-264.

[4] B. A. BoLEy, Upper bounds and Saint-Venant's principle in transient heat conduction, Quart. Appl. Math. , 18 (1960), 205-207.

[5] F. Bofill, AND R. QuintANILla, On the spatial decay of solutions for a class of diffusion-reaction equations, Nonlinear Analysis A, 53 (2003), 1079-1087.

[6] L. C. Evans, Partial Differential Eqations, American Math. Society, Providence Rhode Island, 1998.

[7] J. N. Flavin, R. J. Knops And L. E. Payne, Asymptotic and other estimates for a semi-linear elliptic equation in a cylinder, Quart. Jour. Mech. Appl. Math. , 45 (1992), 617-621.

[8] J. N. Flavin and S. Rionero, Qualitative Estimates for Partial Differential Equation: An introduction, CRC Press, Boca Ration, 1996.

[9] C. O. Horgan, Recent developments concerning Saint-Venant's Principle: An update, Applied Mechanics Reviews, 42 (1989), 295-303.

[10] C. O. Horgan, Recent developments concerning Saint-Venant's Principle: A second update, Applied Mechanics Reviews, 49 (1996), 101-111.

[11] C. O. Horgan AND J. K. KNOWLES, Recent developments concerning Saint-Venant's Principle, Advance in Applied Mechanics, J. W. Hutchinson and T. Y. Wu (editors), 23 Academic Press, New York (1983), 179-269.

[12] C. O. Horgan AND L. E. PAYNE, Phragmén-Lindelöf type results for harmonic functions with nonlinear boundary conditions, Arch. Rat. Mech. Anal, 122 (1993), 122-144.

[13] C. O. Horgan AND L. E. PAYNE, On the asymptotic behavior of solutions of inhomogeneous second order quasi-linear partial differential equations, Quart. Appl. Mathematics, XLVII (1989), 753-771.

[14] C. O. Horgan, L. E. Payne And W. T. Wheeler, Spatial decay estimates in transient heat conduction, Quart. Appl. Mathematics, XLII (1984), 119-127.

[15] Changhao Lin And L. E. Payne, On the spatial decay of ill-posed parabolic problems, Math. Models Methods in Appl. Sci. , 3 (1993), 563-575. 
[16] Changhao Lin and L. E. Payne, A Phragmén-Lindelöf Alternative for a class of quasi-linear second order parabolic problems, Differential and Integral Equations, 8 (1995), 539-551.

[17] Yan Liu And Changhao Lin, Phragmén - Lindelöf alternative results for the stokes flow equation, Math. Inequal. Appl. , 9 (2006), 671-694.

[18] L. E. PAYNe, G. A. PHILlipPin, Decay bounds for solutions of second order parabolic problems and their derivatives $1 \overline{1}$, Math. Inequal. Appl. , 7 (2004), 543-549.

[19] L. E. PAYNe, P. W. SChAFER AND J. C. Song, Growth and decay results in heat conduction problem with boundary conditions, to appear.

[20] L. E. PAYNE AND P. W. SchaEfER, Lower bounds for blow-up time in parabolic problems under Neumann conditions, to appear.

[21] L. E. PAYNe AND P. W. SChAEFER, Lower bounds for blow-up time in parabolic problems under Dirichlet conditions, J. Math. Anal. Appl. , 328 (2007), 1196-1205.

[22] L. E. PAYNE AND J. C. Song, Lower bounds for blow-up time in a temperature dependent NavierStokes flow, Nonlinear Analysis, 35 (1999), 289-286.

[23] R. QUINTANILla, On the asymptotic behavior of solution of some nonlinear elliptic and parabolic equations, Nonlinear Analysis A, 52 (2003), 1275-1293.

[24] R. Quintanilla, On the spatial blow-up and decay for some nonlinear parabolic equations with nonlinear boundary conditions, J. Math. Anal. Phys. (ZAMP), 57 (2005), 595-603.

[25] A. J. C. B. DE S Aint-Venant, Mémoire sur la flexion des prismes, J. Math. Pures Appl. , 12 (1856) 89-189.

[26] B. Straughan, Private Communication. 